Revista da Faculdade de Direito-RFD-UERJ- Rio de Janeiro, n. 28, dez. 2015

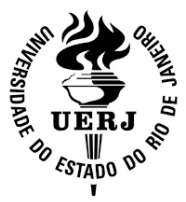

\title{
Justiça Política entre a igualdade e a diferença: explorando a política do reconhecimento de Charles Taylor
}

\section{Por Carlos David Carneiro ${ }^{1}$}

RESUMO: O presente artigo propõe uma análise de "A Política do Reconhecimento", do filósofo canadense Charles Taylor. No curso dessa análise, três dimensões do projeto deste autor são desdobradas, nomeadamente a ideia de uma igual dignidade, como categoria intersubjetiva e corporificada; a ideia de uma "fusão de horizontes", como alternativa ao etnocentrismo e ao relativismo e, por fim, a retomada das razões comunitárias na filosofia política. Ao final, procuro discutir os méritos e problemas dessas dimensões e sua eventual importância para estudos posteriores.

PALAVRAS-CHAVE: Charles Taylor; reconhecimento; igual dignidade; fusão de horizontes; comunitarismo.

ABSTRACT: The purpose of this article is to develop an analysis of Charles Taylor's Politics of Recognition. In this way, I address particularly three dimensions of this work: the idea of equal dignity, as an intersubjective and corporified category; the idea of fusion of horizons, as an alternative to ethnocentrism and relativism and the idea of communitarian reasons in political philosophy. Then, I discuss what I consider to be the strong points and the weaknesses of each of these dimensions, as well their eventual importance to further studies.

KEY WORDS: Charles Taylor; recognition; equal dignitiy; fusion of horizons; communitarianism.

\section{1 - Introdução}

\footnotetext{
${ }^{1}$ Mestre em Direito pela UERJ. Atualmente cursa programa de doutorado na mesma instituição.
} 
Revista da Faculdade de Direito-RFD-UERJ- Rio de Janeiro, n. 28, dez. 2015

A conferência de Charles Taylor para a inauguração do Princeton University's Center for Human Values em 1990, intitulada “A política do Reconhecimento" despertou desde sua publicação uma série de interpretações, críticas e controvérsias ${ }^{2}$. Hoje, mesmo depois de 20 anos, as ideias apresentadas por Taylor na ocasião continuam a despertar interesse e a orientar alguns dos mais importantes debates políticos de nossa época.

O que permite abordagens tão ricas quando diversas é justamente o fato de Taylor não só realizar uma leitura bastante ampla da tradição política que ele identifica com o as democracias liberais, como também explorar algumas de suas fontes morais e possibilidades presentes. Neste artigo, pretendo revisitar "A Política do Reconhecimento", analisando criticamente alguns de seus principais pontos e explorando seus desdobramentos em aspectos que serão apresentados a seguir.

Em primeiro lugar, procurarei expor o conteúdo da conferência, reproduzindo os principais argumentos e pontos levantados por Taylor. Em seguida, proponho-me a fazer uma leitura desses pontos, enfatizando a reconstrução elaborada por Taylor da luta por igual dignidade nas sociedades contemporâneas, sua crença na possibilidade de uma mediação racional de diferenças significativas e, finalmente, sua proposta de um outro modelo de democracia, contraposta àquela que o filósofo canadense chama de democracia do "liberalismo procedimental".

Meu objetivo, ao analisar esses pontos, é o de questionar em que medida o projeto de Taylor em "A Política do Reconhecimento" e outras obras, pode ser útil para se redimensionar os problemas políticos e jurídicos das sociedades contemporâneas em geral e do Brasil em particular.

\section{2 - A importância do "reconhecimento" no debate político contemporâneo}

\footnotetext{
2 Para uma visão geral das diversas abordagens do tema do "reconhecimento", bem como das principais críticas e interlocuções com texto de Taylor, ver MENDONÇA, Ricardo. A dimensão intersubjetiva da autorrealização: em defesa da teoria do reconhecimento. In: Revista brasileira de Ciências Sociais, vol.24, nº 70, PP.143-154, 2009.
} 
Revista da Faculdade de Direito-RFD-UERJ- Rio de Janeiro, n. 28, dez. 2015

Ao iniciar sua discussão acerca do "reconhecimento", Taylor não parte de uma definição ou reconstrução etimológica do termo, mas busca simplesmente constatar sua presença como "dada" na gramática dos conflitos e programas políticos das sociedades contemporâneas. Segundo Taylor, uma gama variada de sujeitos e coletividades, como movimentos nacionalistas, religiosos, minorias étnicas, diversas correntes do feminismo e dos movimentos anti-racistas fariam uso do termo para exprimir suas demandas. A despeito das profundas disparidades e diversidade entre esses movimentos haveria um elo comum que faria do reconhecimento uma categoria significativa. Todos eles, segundo Taylor, tomariam suas identidades como uma variável incontornável da ação política.

Para Taylor, o recurso à identidade, no bojo desses movimentos, consistiria sobretudo no auto-entendimento das pessoas ou grupos sobre si mesmos, suas fontes morais e características fundamentais como seres humanos. Essa mesma identidade, para o filósofo, seria parcialmente formada pelo reconhecimento dos outros considerados relevantes ou sua ausência. Desse modo, uma pessoa ou grupo poderia sofrer um dano ou um sofrimento real caso as pessoas a sua volta formem uma concepção distorcida ou inferiorizante sobre elas.

A questão passa a ser então que um não-reconhecimento ou um reconhecimento distorcido poderia aprisionar as pessoas em um falso e reduzido modo de vida. Para além de uma simples falta de respeito, esse aprisionamento pode causar ainda feridas profundas e gerar autodesprezo nas pessoas e grupos marginalizados. Daí a “ideia" de reconhecimento representar, para Taylor, muito mais do que uma cortesia devida às pessoas, mas uma necessidade humana vital (TAYLOR, 1994, p.25-26).

Uma questão fundamental, no entanto, emerge a partir dessa asserção. Se Taylor considera a ideia de "reconhecimento" como uma necessidade vital do ser humano, como explicar o fato de que só recentemente o termo teria emergido com a relevância política que toma nos dias hoje? De fato, alguns fatores e dilemas da modernidade atual, tais como as novas demandas de expressão estética ou sexual ou mesmo a desagregação normativa da secularização teriam contribuído para tornar mais ostensivas as demandas por reconhecimento. Mas as raízes históricas e filosóficas que tornaram a própria ideia de reconhecimento possível, nos termos hodiernos, remontariam, segundo o filósofo, a 
Revista da Faculdade de Direito-RFD-UERJ- Rio de Janeiro, n. 28, dez. 2015

processos bem anteriores, intimamente relacionados com o próprio advento das sociedades modernas.

O primeiro desses grandes processos teria sido o colapso das hierarquias sociais das sociedades tradicionais, o que teria resultado, nas palavras de Taylor, em uma transição progressiva de uma ética da honra para uma ética da igual dignidade. Aqui, o filósofo parece ter em mente as revoluções liberais e a afirmação da vida cotidiana, que auxiliaram, de certo modo, na desconstrução das leis sociais e das cosmologias que justificavam a desigualdade natural entre os homens. Essa ética, ainda que de modo difuso, teria lançado as bases para a ideia de um "reconhecimento igual de todos os seres humanos". De outro lado, a linguagem da "autenticidade" que emergiu no século XVIII com o movimento romântico e o conjunto de expressões e doutrinas que Taylor intitula de "expressivismo", teria contribuído para a valorização da singularidade de cada sujeito e a legitimação da busca pelo "eu profundo", lançando as bases normativas para a exigência do reconhecimento do que há de único na identidade de cada indivíduo ${ }^{3}$ (TAYLOR, 1994, p.28).

O que estes dois processos mostrariam, tanto em suas lógicas intrínsecas quanto em seus processos históricos constitutivos, é que o encontro com a própria natureza ou a construção da identidade não seria algo monológico ou estático em termos sociais, mas que se forja em contato permanente com o que Taylor chama de "outros relevantes". Os sujeitos, por conta de horizontes normativos que lhe são prévios, constituídos nos processos históricos de suas sociedades, estariam assim inseridos em um contexto de linguagem que os precede e que faz sua própria constituição depender de uma interação direta com este contexto. Além disso, certos bens ou experiências de vida, para Taylor, só seriam inteligíveis quando os experimentamos e partilhamos seu significado com outras pessoas. Alguns dos bens mais relevantes na vida, para o filósofo, aliás, só seriam acessíveis quando comumente gozados ${ }^{4}$. (TAYLOR, 1994, p.33).

\footnotetext{
${ }^{3}$ A reconstrução da "genealogia moral do ocidente", na qual a firmação da ideia de dignidade por oposição à de honra e o surgimento do expressivismo emergem como algumas das fontes morais é apresentada de modo mais detalhado por Taylor na obra "As fontes do Self". A este respeito ver TAYLOR, Charles. As fontes do Self. São Paulo: Edições Loyola, 1997

${ }^{4}$ Neste ponto, talvez seja útil explorar alguns dos pressupostos filosóficos utilizados por Taylor. Em artigo intitulado "Bens Irredutivelmente Sociais", Taylor, utilizando os termos da teoria da linguagem de
} 
Revista da Faculdade de Direito-RFD-UERJ- Rio de Janeiro, n. 28, dez. 2015

É justamente o pressuposto da construção dialógica da identidade do ser humano ou a necessidade do ser-com-o-outro em sociedade que tornam, no pensamento de Taylor, o reconhecimento uma categoria vital nas discussões políticas no mundo contemporâneo. E os processos de luta pelo igual reconhecimento e a emergência de uma ética da autenticidade teriam proporcionado a esta ideia a primazia que toma nos dias de hoje. Em resumo, para Taylor, em um plano íntimo, estaríamos cientes de como a identidade pode ser formada ou deformada pelo contato com os outros relevantes. E, em um plano social, teríamos uma política progressiva, aberta pelos processos históricos e filosóficos mencionados, do reconhecimento do igual valor de todos os seres humanos.

\section{3 - A Política do Universalismo e a Política da Identidade}

Deixando de lado a questão do reconhecimento na esfera íntima, Taylor passa a se concentrar então na expansão do reconhecimento âmbito esfera pública. Para o filósofo, esta noção teria ganho expressão sobre duas diferentes rubricas, associadas aos dois processos anteriormente elencados, relativos, respectivamente, ao igual reconhecimento e à emergência de uma ética da autenticidade. Taylor passa a abordar então as diferenças e tensões entre o que chama de "política do universalismo" e "política da identidade".

A política do universalismo, na qual estiveram ancoradas as grandes revoluções da era moderna e mesmo as reivindicações operárias posteriores, como teria mostrado T.H. Marshall, estaria fortemente calcada na equalização dos direitos e garantias

Saussure, defende a existência de uma relação circular entre o código social (langue) e os atos de fala particulares (parole). Para o filósofo canadense, a ação expressiva parte do sujeito, mas se dá em relação a um pano de fundo que lhe confere significado. Assim, os atos de fala particulares pressupõem a existência desse pano de fundo, mas este é também constantemente recriado neles. Na interação expressiva entre o sujeito e o pano de fundo, alguns bens só são compreendidos na presença do outro. Haveria para Taylor exemplos óbvios da vida particular como as relações amor e amizade. No entanto, passando para um plano político, Taylor acredita que relações sociais igualitárias são tipos de bens que só fazem sentido quando vivenciados conjuntamente. E é por isso que, em sua filosofia, o estabelecimento de padrões públicos de reconhecimento tornam-se tão fundamentais. A este respeito, ver TAYLOR, Charles. Argumentos Filosóficos. São Paulo: Edições Loyola, 2000, p. 143-161. 
Revista da Faculdade de Direito-RFD-UERJ- Rio de Janeiro, n. 28, dez. 2015

fundamentais. Ainda que haja fortes divergências acerca do conteúdo dessa equalização (igualdade formal, igualdade de oportunidades, igualdade substantiva, etc.) o fato é que, com sua emergência, tornou-se corrente a ideia de que não deveriam mais existir cidadãos de primeira e segunda classe (TAYLOR, 1994, p.37). Para Taylor, igualdade entrara de vez no debate político e, mesmo que sob diversas perspectivas, passara a orientar os programas das mais diversas correntes políticas.

Posteriormente à política do universalismo, no entanto, ter-se-ia forjado ainda um segundo processo de amplas consequências políticas, dessa vez baseado na noção moderna de identidade. Haveria também neste processo uma base universalista, uma vez que, segundo o filósofo, todos e todas deveriam ser reconhecidos por sua identidade única. Mas, ao contrário da política do universalismo, aqui o reconhecimento significaria algo a mais, uma vez que o que se pede é que se reconheça, em um indivíduo ou grupo, sua distinção em relação aos que o cercam. Nisto, em poucas palavras, consistiria a "política da identidade".

Apesar de suas semelhanças e possíveis convergências, as duas leituras acerca do reconhecimento, baseadas na política do universalismo e na política da identidade, gerariam certos dilemas e conflitos em relação ao modo de tratar a diferença na esfera pública, principalmente no que diz respeito à ideia de "não discriminação" defendida por cada uma destas políticas.

A política do universalismo lutaria por formas de não-discriminação cegas em relação às diferenças. Enquanto isso, por sua vez, a política de identidade buscaria redefinir a própria noção de não-discriminação, buscando nas distinções entre as condições históricas e no contexto de cada grupo ou classe a base de uma justificativa positiva para um tratamento diferenciado. Para a política da identidade a "neutralidade" apareceria como uma discriminação disfarçada de universalidade, causando danos sobretudo aos grupos e classes marginalizados.

As intuições fundamentais de ambas as políticas, deste modo, poderiam ser resumidas da seguinte forma: para a política da universalidade todas as pessoas deveriam ser respeitadas segundo o que todos têm em comum. Para a política da identidade, por sua vez, seria preciso reconhecer e mesmo promover as particularidades. O que a primeira 
Revista da Faculdade de Direito-RFD-UERJ- Rio de Janeiro, n. 28, dez. 2015

reprova na segunda é que ela viola o princípio da não-discriminação. O que a segunda reprova na primeira é que ela acaba por forçar as pessoas a um molde de convivência e existência homogêneo que não parece verdadeiro para elas.

Como resolver ou, ao menos, mediar os conflitos entre as duas políticas? Haveria algum modo de promover a abertura à diferença em sociedades assentadas sob o imaginário da política do universalismo? Taylor busca na própria tradição que dá vazão à discussão sobre o reconhecimento possíveis respostas a esta pergunta. Dito de outro modo, o que ele parece questionar é se visão da igual dignidade pode ou não, de fato, promover ou reconhecer de modo adequado as diferenças.

\section{4 - O Retorno à Rousseau e Kant}

Taylor associa a emergência da política da igual dignidade no ocidente a duas maneiras distintas de formulação, que poderiam, por sua vez, serem associadas aos nomes de Rousseau e Kant. Isso não significa, para o filósofo, que suas influências se fizeram proeminentes em todos os desdobramentos posteriores destes modelos, mas que, de alguma forma, eles foram seus principais expositores nos primórdios desta política.

Teria sido Rousseau o primeiro a produzir reflexões marcantes sobre a importância do respeito igual e seu embasamento para a liberdade. Como é sabido, Rousseau elaborou em seu tempo uma contraposição entre uma situação de liberdadeem-igualdade e uma outra caracterizada pela hierarquia e dependência em relação aos outros. No estado de dependência, se é dependente dos outros não só porque estes detêm o poder político ou oferecem condições de possibilidade aos projetos acalentados pelo indivíduo, mas, acima de tudo, porque seria algo constitutivo do comportamento humano ansiar pela estima alheia. E aquele que depende dessa estima, para Rousseau, seria como um "escravo da opinião" e, por consequência, alguém que não poderia ser considerado livre.

A questão mudaria completamente de figura, no entanto, quando a reciprocidade ou a necessidade de estima do outro passa a ser constituída em condições de igualdade. 
Revista da Faculdade de Direito-RFD-UERJ- Rio de Janeiro, n. 28, dez. 2015

Para Taylor, a tese de Rousseau poderia ser sintetizada da seguinte maneira: "uma reciprocidade perfeitamente equilibrada remove o espinho da nossa dependência da opinião dos outros e torna-a compatível com a liberdade. Isto porque a reciprocidade completa, juntamente com a unidade de um objetivo daí resultante, assegura que, ao seguir a opinião dos outros, não estou a ser, de modo algum, forçado a sair de mim mesmo. (TAYLOR, 1994, p.48).

Assim, para Rousseau, é a unidade de todos em um sistema não-hierárquico que faz possível a igualdade de estima, ao passo em que essa igualdade torna-se essencial para a própria unidade de propósito estabelecida por este sistema. Sob a égide de uma "vontade geral", todos os cidadãos virtuosos devem ser honrados da mesma maneira. Segundo Taylor, surge, a partir dessa formulação, uma importante variável do discurso sobre dignidade em nossa era.

Para o filósofo canadense, é essa nova crítica da honra que leva não a uma mortificação solitária, mas a uma política da igual dignidade, política essa que teria sido adotada e eternizada também por Hegel em sua famosa dialética do senhor e do escravo. Contra o antigo discurso sobre os malefícios do orgulho, Hegel considerou como fundamental a hipótese de que podemos florescer somente até o ponto em que somos reconhecidos por nossos pares de interação. Cada consciência busca o reconhecimento de outra consciência e isso não seria um signo da falta de virtude. No entanto, essa luta por reconhecimento só poderia achar uma solução satisfatória em um regime de reconhecimento recíproco entre iguais, no qual não haja ganhadores e perdedores, mas uma sociedade em que haja um "nós" que seja um "eu” e um “eu” que seja um "nós". Nisso, Hegel também acompanharia as intuições fundamentais de Rousseau acerca da reciprocidade. (TAYLOR, 1994, p.50).

No entanto, se por um lado Taylor reconhece que Rousseau inaugurou, de certo modo, a política da igual dignidade, considera, por outro, que sua solução é extremamente falha. Isso porque a igualdade de estima, colocada nos termos de Rousseau, parece requerer uma unidade de objetivo que parece incompatível com qualquer tipo de reconhecimento da diferença. Em Rousseau, três coisas parecem inseparáveis: 1) a liberdade (como não-dominação); 2) a ausência de papéis diferenciados e 3) uma unidade 
Revista da Faculdade de Direito-RFD-UERJ- Rio de Janeiro, n. 28, dez. 2015

propósitos muito coesa. Todos nós devemos depender, no bojo desse esquema, da vontade geral para que não surjam formas bilaterais de dependência. Essa fórmula, como não poderia deixar de ser, teria dado azo à algumas das mais sangrentas tiranias homogeneizantes, começando pelos jacobinos até os regimes totalitários do século XX. (TAYLOR, 1994, p.51).

Diante desse diagnóstico, Taylor passa então a questionar se a variante "kantiana" da política da igual dignidade oferece uma alternativa melhor. Em um primeiro momento, essa variante parece não sofrer dos mesmos problemas da tríade rousseauniana, uma vez que tenta abstrair o debate acerca da igualdade de direitos do exercício de uma "vontade geral" ou de uma "indiferenciação" de papéis sociais". No entanto, ainda assim, a variante kantiana, segundo o autor, ainda estaria sujeita à crítica de homogeneizante, por não abrir, por sua vez, um espaço devido para a diferença.

Isto porque, para Taylor, prima facie, esta tradição teria se consolidado com base em uma noção forte de "neutralidade", segundo a qual a igualdade requereria uma aplicação uniforme dos direitos. Ao basear sua ideia de igual dignidade no respeito à autonomia dos sujeitos, a tradição kantiana buscaria um tipo de universalidade formal incapaz de captar as diferenças demandadas por indivíduos ou grupos sociais, bem como de se abrir para experiências éticas advindas de suas sensibilidades. Dessa forma, a noção de que o corpo de direitos deveria ser aplicado de formas distintas devido a distinções de ordem econômica e cultural, pareceria hostil ou sem sentido para esta tradição, que as entenderia como vantagens indevidas ou demandas incompatíveis com as exigências de universalidade.

Taylor identifica a variável kantiana como a fonte teórica principal da corrente que hoje seria majoritária na interpretação da tradição liberal, cuja leitura da política da igual dignidade parece estar ancorada fortemente na necessidade da aplicação uniforme dos direitos. Assim, consideradas ambas as tradições centrais da política da igual dignidade, a fundamentação da política da diferença chegaria a um impasse. Ao mesmo tempo em que a variante rousseauniana seria autoritariamente homogeneizante, a variante kantiana baseada na neutralidade seria, por motivos inversos, hostil à diferença. Mas seriam estas as únicas interpretações possíveis? 


\section{5 - Liberalismo procedimental e razões comunitárias}

Para responder à questão da seção anterior, Taylor toma como exemplo a discussão acerca das leis de proteção à cultura francesa aprovadas por sua Província, o Quebec. Segundo Taylor, o Quebec aprovou leis que regulam, por exemplo, a obrigatoriedade para certos grupos de matricularem seus filhos em escolas francófonas ou mesmo que empresas que possuam acima de 50 funcionários devem ser geridas em francês. Uma terceira lei regulava, ainda, a veiculação de placas comerciais exclusivamente na língua francesa ${ }^{5}$.

De modo geral, uma série de restrições ao arbítrio individual e em favor da cultura francesa foram estabelecidas pelo governo em nome do objetivo coletivo de sobrevivência da comunidade, o que em outras realidades seria facilmente desautorizado com base no entendimento corrente acerca do significado da "autonomia" ou mesmo com base na própria Carta de Direitos aprovada pelo Canadá, onde se situa a província do Quebec $^{6}$. Seria essa política algo admissível ou ela feriria de morte a política da igual dignidade, requerida pelas democracias liberais?

Segundo Taylor, hoje a leitura predominante da democracia estaria fortemente identificada com o autor chama de "liberalismo procedimental". Autores como Ronald Dworkin, por exemplo, acreditariam que a uma sociedade liberal bem-sucedida não poderia adotar nenhuma visão particular de vida boa ou bem substantivo, sob o risco de prejudicar a própria base democrática da sociedade. Aqui, antes de tudo, uma sociedade

\footnotetext{
${ }^{5}$ Segundo o próprio Taylor, esta terceira lei foi declarada inconstitucional pela Suprema Corte do País.

${ }^{6}$ No caso concreto, segundo Taylor, o tratado de Meech Lake reconheceu o Quebec como uma "comunidade distinta", reconhecendo ainda essa distinção como base para a interpretação judicial de suas leis, inclusive aquelas dispostas na própria Carta de direitos (TAYLOR, 1994, p.52-53). Posteriormente, no entanto, esse acordo foi derrotado pelo desacordo entre as províncias e no início da década de 90 um novo acordo foi firmado, sendo também derrotado posteriormente. Até os dias de hoje, o Quebec não ratificou a Carta de Direitos do Canadá e a controvérsia em relação a seu status permanece. Nesse sentido, cf. http://www.thecanadianencyclopedia.ca/en/article/meech-lake-accord/.
} 
Revista da Faculdade de Direito-RFD-UERJ- Rio de Janeiro, n. 28, dez. 2015

bem-ordenada está identificada com uma sociedade de sujeitos autônomos em relação à coação externa ou a qualquer visão de bem exterior ao próprio sujeito.

Como pode-se antever, o liberalismo, quando lido dessa forma, excluiria totalmente a pretensão do Quebec em relação ao reconhecimento de suas peculiaridades e suas pretensões de bem coletivo. Poder-se-ia, em última instância, argumentar em termos procedurais que a língua francesa poderia ser considerada como um recurso que os indivíduos podem dispor para seus próprios objetivos. Mas, para Taylor, este tipo de argumentação não capturaria o que realmente está em jogo, ou como os sujeitos envolvidos de fato compreendem a questão, na qual pesaria a própria ideia de sobrevivência cultural de uma coletividade.

$\mathrm{O}$ argumento do liberalismo procedimental, segundo Taylor, é que uma sociedade que impõe valores morais ou objetivos coletivos aos seus cidadãos é, de certa forma, uma sociedade que viola os direitos fundamentais dessas pessoas, uma vez que a imposição externa de padrões significaria inevitavelmente uma restrição indevida à autonomia individual. Em segundo lugar, ao estabelecer metas coletivas, uma sociedade estaria automaticamente criando um "dentro" e um "fora", um "nós" e um "eles" que poderia se tornar uma prática necessariamente discriminatória. Haveria forma de fugir deste impasse?

Segundo Taylor, é possível propor um "modelo alternativo", ainda dentro dos marcos liberais, capaz de reformular a ideia da igual dignidade abrindo-a para o reconhecimento da diferença e para as pretensões de sociedades como a do Quebec. Para este modelo, seria legítimo que uma sociedade optasse por uma concepção de vida boa ou estabelecesse suas metas coletivas, com a condição de não depreciar aqueles que não compartilham dessas metas. De acordo com o modelo alternativo, uma sociedade liberal se caracterizaria pelo modo como trata as minorias, incluindo aqueles que não compartilham as definições públicas do "bem” e pelos direitos que garante a todos os seus membros ${ }^{7}$.

\footnotetext{
${ }^{7} \mathrm{O}$ respeito às minorias como elemento normativo da democracia aparecerá e será desenvolvido em textos posteriores de Taylor. A este respeito, ver TAYLOR, Charles. The dynamics of Democratic Exclusion. In: Journal of Democracy. Vol.9, no. 4, 1998b. p.143-156. e TAYLOR, Charles. Democratic Exclusion (and
} 
Revista da Faculdade de Direito-RFD-UERJ- Rio de Janeiro, n. 28, dez. 2015

Direitos "canônicos" da tradição liberal, como o direito à livre-expressão, à liberdade, à vida deveriam ser sempre protegidos, não estando sujeitos aos bens estabelecidos coletivamente. Mas não haveria que se falar, por exemplo, em um direito fundamental à liberdade de gerir uma empresa em inglês, como no caso do Quebec. Para Taylor, o modelo alternativo estabelece uma clara distinção entre direitos fundamentais e privilégios ou imunidades passíveis de restrições pelas políticas públicas definidas na arena política. Mas se o modelo de Taylor, considerando estes esclarecimentos, pode ser considerado viável, resta perguntar por que seria este um modelo desejável ou ao menos superior ao liberalismo procedimental.

Ao que parece, para Taylor, e isso ficará mais claro adiante, o liberalismo procedimental parece não capturar dimensões importantes da vida coletiva e das identidades inerentes aos sujeitos. Ao tratar essas dimensões como uma "não-parte" da política, estar-se-ia contribuindo, segundo o filósofo, para a erosão dos laços comunitários e o respeito devido aos indivíduos e grupos. O modelo alternativo, por sua vez, teria o condão de manter o que há de bom na tradição liberal (a política da igual dignidade e a defesa dos direitos fundamentais) com a assunção das diferenças e avaliações fortes na esfera pública.

Para Taylor, tensões ou divergências acerca do que seriam direitos canônicos ou restrições legítimas ao arbítrio individual seriam inevitáveis neste processo e deveriam ser resolvidos através do próprio autogoverno coletivo dos cidadãos. No entanto, essas tensões não seriam maiores do que as já enfrentadas nas sociedades atuais, como as tensões entre liberdade e igualdade ou prosperidade e justiça ${ }^{8}$. Além de considerar o modelo alternativo superior pelos motivos anteriormente esboçados, Taylor considera ainda que um liberalismo procedimental rígido e hostil a diferença se tornará impraticável

it remedies?). In: Dilemmas and Connections. Cambridge, MA: Harvard University Press, 2011. 124-145.

${ }^{8}$ Aqui Taylor parece se referir respectivamente aos embates hoje existentes entre defensores do Estado mínimo x socialistas ou defensores de um estado equitativo e às distorções sociais causadas pela desigualdade de renda. Em relação ao primeiro debate, para um quadro teórico mais geral, ver GARGarella, Roberto. As Teorias da Justiça Depois de Rawls: Um Breve Manual de Filosofia Política. São Paulo: WMF Martins Fontes, 2008. 
em um mundo cada vez mais plural e demandante de reconhecimento das diferenças ${ }^{9}$ (TAYLOR, 1994, p.60-61).

\section{6 - A política do Reconhecimento}

Com a exposição de um modelo "alternativo" de liberalismo, como acabamos de delinear,Taylor oferece sua própria resposta à questão da existência ou não de uma política da igual dignidade aberta às diferenças. Mas para ele, a questão pode e deve ser formulada ainda em outros termos, capazes de enfrentar em última instância, os obstáculos à política do reconhecimento nas sociedades atuais.

Em primeiro lugar, para o filósofo, é preciso problematizar a ideia de que o liberalismo, por ser supostamente neutro e baseado na autonomia individual pode servir de parâmetro ótimo para o encontro de todas as culturas. A própria noção de neutralidade na qual a tradição liberal está baseada seria produto de uma visão muito particular de valores ocidentais que guardariam suas raízes em interpretações da tradição cristã ${ }^{10}$. Assim, mesmo o fundamento da neutralidade, implicaria no reconhecimento de fundamentos "substantivos" fortes de uma cultura específica. Taylor levanta esta questão, ao que parece, não com o intuito de minar a legitimidade da tradição liberal, mas para salientar o fato de que as discussões substantivas sobre valores e bens na política não podem ficar ofuscadas (ou mesmo alijadas) sob pretensões de neutralidade, mas devem

\footnotetext{
${ }^{9}$ Por fugir do escopo do artigo, não discutirei essa questão específica com a propriedade que merece. Mas o debate acerca da "neutralidade" do Estado ainda permanece controversa, ainda mais quando, muitos dos considerados "liberais", por sua vez rejeitam a ideia de um procedimentalismo formal puro. Esse é o caso por exemplo de Will Kymlicka, que defende que a proteção de bens culturais pode não ser incompatível com a neutralidade estatal. Kymlicka cita, por exemplo, a possibilidade de o Estado garantir um leque adequado de opções culturais aos indivíduos, sem, no entanto, tomar partido por nenhuma delas. Aqui a neutralidade seria preservada, sem, no entanto, negar a existência de bens culturais a serem protegidos. A este respeito, ver KYMLICKA, Will. Filosofia política contemporânea. Martins Fontes: São Paulo, 2006, p.281 e ss.

${ }^{10}$ Sobre a relação entre as instituições políticas e jurídicas consagradas no ocidente e a tradição cristã, uma narrativa interessante é apresentada em PRODI, Paolo. Uma história da justiça. Martins Fontes: São Paulo, 2005.
} 
Revista da Faculdade de Direito-RFD-UERJ- Rio de Janeiro, n. 28, dez. 2015

ser expostas para que os diversos grupos tenham assento real na formação da vida comunitária.

Em segundo lugar, se o objetivo até então era de tentar oferecer uma base de legitimidade a objetivos coletivos e a pretensões relativas à sobrevivência dos grupos, também torna-se necessário assentar as condições através das quais a ideia de um igual respeito pelas culturas possa emergir em uma sociedade plural ou no diálogo entre sociedades. Para além da sobrevivência, a abertura à diferença deve significar também um reconhecimento do valor de todos os envolvidos (TAYLOR, 1994, p.64).

A reivindicação de um "igual valor", segundo Taylor, fora feita ou expressa de diversas formas pelos atores políticos de nossa era, movidos, em seus próprios termos, pela desigualdade, exploração ou injustiça. A novidade das sociedades contemporâneas seria justamente a adição, a todas as motivações políticas, da ideia de "reconhecimento". Isto porque, segundo o filósofo, houve uma propagação da noção, discutida no início, de que somos formados segundo o reconhecimento que recebemos dos outros. Poderíamos dizer, na esteira do filósofo, que graças a essa ideia um reconhecimento distorcido agora é considerado como parte do mesmo rol dos adversários da política da igual dignidade, como a desigualdade, a exploração ou a injustiça (TAYLOR, 1994, p.64).

Segundo Taylor, um dos autores chaves para a emergência da ideia de "reconhecimento" teria sido Frantz Fanon, com sua obra "Os Condenados da Terra". Para Fanon, militante anti-colonial, a maior arma dos colonizadores teria sido a própria imposição de uma auto-imagem inferiorizada aos povos dominados. A despeito dos métodos violentos recomendados por este autor, Taylor sugere que o programa político de uma luta pela superação da auto-imagem face ao opressor teria sido desde então largamente empregada, influenciado desde os vários tipos de feminismo até as discussões atuais acerca do multiculturalismo.

Formulado desta maneira, o reconhecimento seria um requisito da igual dignidade, da chance igual de forjar uma identidade não distorcida e altiva do próprio grupo ou sujeito. Essa extensão da política da igual dignidade para uma nova seara geraria para Taylor a necessidade do estabelecimento de uma presunção de valor igual entre as culturas. Para o filósofo canadense, as culturas humanas que animaram a vida de 
Revista da Faculdade de Direito-RFD-UERJ- Rio de Janeiro, n. 28, dez. 2015

sociedades inteiras durante um período considerável de tempo, provavelmente têm coisas importantes para dizer a todos os seres humanos e seria preciso partir dessa presunção para lhes garantir o respeito devido. (TAYLOR, 1994, p.66).

A presunção do valor igual, segundo Taylor, deveria, no entanto, ser testada concretamente, através de uma "fusão de horizontes", no qual os dialogantes poderiam reduzir a distância entre si produzindo vocabulários de comparação e meios de avaliação dos contrastes entre seus horizontes e culturas. Essa solução, apesar das inúmeras controvérsias filosóficas que implica, seria uma alternativa tanto às tentativas de lidar com a diferença a partir de um cânone pré-definido quanto às tentativas relativistas de minar a questão enquanto tal, o que, para Taylor, não implicaria no desaparecimento das opressões, mas reforçaria a negação das razões do outro. (TAYLOR, 1994, p.70-71).

\section{Segunda Parte: Explorando a Política do Reconhecimento}

A política do reconhecimento de Charles Taylor, como dito de início, teve o condão de influenciar e mesmo redimensionar uma série de debates na teoria e filosofia política contemporânea, sendo que essa influência também extrapolou expressamente o contexto e as preocupações iniciais do autor, ganhando uma série de roupagens e interpretações próprias. Nessa segunda parte do artigo, gostaria de me dedicar a alguns pontos que considero centrais à análise da conferência, procurando justificar suas escolhas e importância para possíveis desenvolvimentos posteriores.

O primeiro deles diz respeito justamente à igual dignidade, categoria que, como visto, estaria na base tanto do que Taylor chama de política do universalismo quanto de sua política da diferença. Acredito que as formulações de Taylor a este respeito, por terem o condão de recuperar a dimensão histórica e intersubjetiva dessa categoria, pode nos ajudar a enfrentar certos dilemas das políticas e instituições igualitárias nas sociedades contemporâneas, tanto no nível da gramática política normativa, quanto da análise sociológica da institucionalização da igualdade presumida. Em outras palavras, como procurarei discutir a seguir, a abordagem de Taylor em relação à igual dignidade, pode 
Revista da Faculdade de Direito-RFD-UERJ- Rio de Janeiro, n. 28, dez. 2015

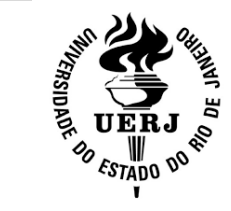

Pág in a | 191

nos levar tanto a redimensionar os requisitos normativos das práticas igualitárias como servir de instrumento mais acurado em termos no nível da teoria social, uma vez que recupera a dimensão histórica e comunicativa de categorias não raro apenas presumidas nos debates políticos e jurídicos das democracias contemporâneas.

Em segundo lugar, o apelo de Taylor a uma fusão de horizontes parece colocar os termos do debate político em um espectro distinto do relativismo e do etnocentrismo que, de certa forma, polarizam o debate contemporâneo. Explorar a possibilidade de mediação racional das diferenças substantivas no espaço público parece ser um elemento importante para a concretização do reconhecimento igual entre indivíduos e grupos sociais, motivo pelo qual deter-me-ei também neste tema.

Por fim, e de um modo mais importante, a remissão que Taylor faz às razões da comunidade e do autogoverno coletivo parece contrastar fortemente com as leituras atomistas acerca dos padrões de interação social que marcam o pensamento contemporâneo, com consequências importantes não só para a gramática da política pública quanto para a análise teórica de nossas sociedades. Seria este um modelo desejável e capaz de promover de modo mais consistente as comunidades políticas, como as compreendemos hoje? Essas são algumas das questões que desejo explorar nesta segunda parte do artigo.

\section{7 - A marcha inexorável da igualdade}

Ao enumerar as razões centrais da emergência da política do reconhecimento, ou, ao menos, os processos que tornaram possíveis esta emergência, Taylor refere-se à ideia de igual dignidade e ao colapso da antiga ideia de honra. É sobretudo em um artigo do sociólogo Peter Berger (BERGER, 1983) que o filósofo canadense busca as chaves mestras deste processo, que estaria na base da própria transição para a modernidade.

Segundo Berger, a honra seria comumente entendida como um conceito aristocrático ou típico de sociedades marcadas por alguma forma de ordem social hierárquica. Ao menos no ocidente, as noções de honra teriam sido fortemente 
Revista da Faculdade de Direito-RFD-UERJ- Rio de Janeiro, n. 28, dez. 2015

influenciadas, segundo este autor, pelos códigos medievais de cavalaria e estariam enraizadas nas estruturas sociais do feudalismo. A dignidade, por sua vez, estaria associada ao colapso dessas mesmas hierarquias, quando passou-se a considerar antes humanidade intrínseca dos sujeitos, a despeito dos papéis sociais e suas normas. Isso ficaria bastante claro em formulações como a do Preâmbulo da Declaração Universal de Direitos Humanos, que defende que "estes direitos pertencem ao indivíduo independente de sua raça, cor ou credo religioso".

Isso não significa, é claro, que na própria noção de honra a dignidade humana não fosse reconhecida de alguma forma. Segundo Berger, a humanidade de cada um então era concebida a partir dos papéis e normas estabelecidos pela sociedade, o que garantia uma profunda dignidade, em seus próprios termos, aos mais diversos estratos sociais. O que tornará peculiar a nova noção de dignidade é a maneira pela qual a humanidade intrínseca de cada um está relacionada com os outros e com as instituições sociais. Em mundo atravessado pela dignidade, segundo Berger, o indivíduo pode descobrir sua identidade somente emancipando a si mesmo dos papéis socialmente a ele ou ela impostos. A história passa a ser então somente uma sucessão de mistificações da qual o indivíduo deveria se livrar a fim de alcançar sua “autenticidade”. (BERGER, 1983, p.177).

Mas o que teria gerado a transição da qual fala Berger, e, como vimos, Taylor, advinda da dissolução do conceito de honra e da emergência da noção de dignidade ao longo da história? Para Berger, é impossível formular uma teoria monocausal acerca deste processo. Muito provavelmente, segundo ele, a maioria dos fatores comumente citados a este respeito exerceram um papel importante neste processo: tecnologia e industrialização, burocracia, urbanização e crescimento populacional, o vasto incremento da comunicação entre os mais diversos grupos humanos, a mobilidade social, a pluralização dos mundos sociais e a profunda metamorfose no contexto em que as crianças são criadas. Todos estes fatores teriam forjado a "subjetivação" moderna, fragmentando e tornando implausíveis os tipos de coesão e estabilidade dos antigos papéis sociais (BERGER, 1983, p.178)

Um ponto importante deste processo de subjetivação, assinalado por Berger, é que a reciprocidade entre indivíduo e sociedade, entre identidades subjetivas e a identificação 
objetiva via papéis sociais, torna-se uma espécie de "luta". As instituições deixam de ser algo como a "casa do indivíduo" para tornarem-se realidades opressivas e distorcivas da identidade individual $^{11}$ (BERGER, 1983, p.179). Aqui o duplo processo de luta por reconhecimento, assinalado por Taylor, toma vez. Ao sentir-se munido de uma dignidade igual a de seus pares, o indivíduo luta para transformar as estruturas e instituições sociais que considera injustas. Por outro lado, luta ainda para ver reconhecido pela sociedade aquilo que tem de único e distintivo de todos os demais.

Por mais que tanto a luta contra a discriminação injusta quanto a luta pelo reconhecimento da diferença tenham por base o sentimento da existência de uma dignidade intrínseca aos indivíduos que deve ser reconhecida, gostaria de focar, antes de mais nada no aspecto iminentemente igualitário dessa luta. Isto porque, comumente, a ideia de reconhecimento tem sido associada como uma categoria restrita aos movimentos identitários e às lutas multiculturais ${ }^{12}$. Se, no entanto, a reconstrução do pensamento de Taylor que vim levando a cabo até aqui tiver pertinência, a categoria do "reconhecimento" também pode (e deve) ser associada à luta por igual respeito nas sociedades contemporâneas ${ }^{13}$.

Esta tese parece ainda ser reforçada se pensarmos que os códigos de honra e estima, cuja dissolução é apontada tanto por Berger como por Taylor não anulam as formas de diferenciação ou discriminação presentes nas sociedades contemporâneas. Os

\footnotetext{
${ }^{11}$ Berger parece, no entanto, ver de modo bastante ambivalente essa nova relação entre indivíduo e sociedade gerada pela dissolução da noção de honra. Ao mesmo tempo em que reconhece o avanço gerado pela afirmação de direitos fundamentais e rechaça a nostalgia de "direita" em relação à ética da honra, Berger considera que ver as instituições sempre como "opressoras", como o faz a visão de "esquerda" acerca da ética da igual dignidade, falha ao não levar em conta requisitos essenciais dos indivíduos, como a própria necessidade de uma ordem. Para Berger, sem instituições solidamente constituídas, tanto os indivíduos como as sociedades cairiam em um caos desumanizador. A este respeito ver BERGER, Peter. On the Obsolescence of the Concept of Honour. In: HAUERWAS, Stanley; MACINTYRE, Alasdair. Revisions: Changing Perspectives in Moral Philosophy. Notre Dame: University of Notre Dame Press,1983. p. 180.

${ }^{12}$ Essa parece ser, por exemplo, a leitura que Nancy Fraser faz, ao menos em seus primeiros escritos sobre o tema, da política do reconhecimento de Charles Taylor. A Este respeito ver: FRASER, Nancy. "From Redistribution to Recognition? Dilemmas of Justice in a 'Postsocialist Age". In: Justice Interruptus - Critical Reflections in a 'Postsocialist Condition. Londres. Routlege, $\overline{\mathrm{pp}} .11-39,1997$

${ }^{13}$ A defesa de uma luta por igual respeito como uma luta por reconhecimento na obra de Taylor já fora assinalada por Simon Thompson em THOMPSON, Simon. The political theory of recognition: a critical introduction. Cambridge, UK/Malden: Polity, 2006.
} 
Revista da Faculdade de Direito-RFD-UERJ- Rio de Janeiro, n. 28, dez. 2015

próprios exemplos citados por Taylor, como a luta pelos direitos civis dos negros ou mesmo o feminismo em suas primeiras fases de luta por direitos políticos, são exemplos de como o igual respeito não está dado de uma vez por todas, mas encontra vários obstáculos e desafios nos dias de hoje. Da mesma forma, como vimos, Berger enxerga a relação fundamental dos indivíduos nas sociedades atuais, como uma relação de tensão permanente, na qual a ideia de "luta" configura um padrão de relação central, que se reproduz ao longo do tempo. Uma pergunta que emerge, então, é como essa luta por igual respeito ainda permanece central em sociedades que, em sua maioria, já reconhecem no nível formal e das representações os direitos fundamentais relacionados à igual dignidade. Talvez, retornar a um outro artigo do autor, possa clarificar a questão e aproximar seu pensamento dos dilemas atuais enfrentados por sociedades ditas "periféricas", como a sociedade brasileira.

Em um artigo intitulado "Seguir uma Regra", por exemplo, Taylor distingue duas dimensões da nossa capacidade de seguir instruções ou obedecer regras sociais. A dimensão mais comum, reconhecida pela tradição intelectual, seria uma maneira intelectualista, como se as regras que seguimos estivessem relacionadas aos nossos pensamentos e representações. De outro lado, seguindo o sociólogo Pierre Bourdieu, Taylor defende que o pano de fundo de nossas intuições morais é em larga medida corporificada, estando presente em nossas ações de maneira inarticulada. Aqui, Taylor se vale da noção de "habitus" cunhada por Bourdieu para explicar a existência de regras pessoais que não estão na base das representações, mas ainda assim, possuem eficácia social profunda nas práticas e instituições:

\footnotetext{
"Uma regra só existe nas práticas que anima, e não requer e pode não ter nenhuma formulação expressa. Como pode ser isso? Somente por meio de nossa compreensão corporificada. É a isso que Bourdieu tenta chegar com a noção de habitus. Trata-se de um sistema de disposições duradouras e transponíveis, disposições de comportamento corporal, agir, postar-se ou gesticular de certa maneira. Uma disposição corporal é um habitus quando codifica uma certa compreensão cultural. Nesse sentido, o habitus sempre exibe uma dimensão expressiva. Ele dá
} 
expressão a certos significados que as coisas e as pessoas têm para nós, e é precisamente ao dar essa expressão que faz esses significados existirem. (TAYLOR, 1995, p.194).

Dessa maneira, se entendermos o habitus como um pano de fundo, corporificado, que forma uma base inarticulada de nossa ação social, podemos muito bem em um nível sociológico, encontrar uma distância entre a igualdade assentada no nível das representações e os padrões de distinção e desigualdade, de desqualificação e discriminação a nível inarticulado, com eficácia real nas nossas práticas e padrões de interação social. Foi justamente essa distância que foi explorada pelo sociólogo Jessé Souza ao interpretar a sociedade brasileira com base nos pensamentos de Taylor e Pierre Bourdieu.

Para Jessé Souza, a sociedade brasileira estaria marcada frontalmente pela produção social de uma "ralé estrutural", uma classe inteira de indivíduos tidos como párias sociais pela sociedade e, em certa medida, internalizando sua própria marginalização. Isso tudo, é claro, funcionando sob uma sociedade que reconhece todos os direitos e garantias da tradição constitucional e que professa, no nível das representações, uma política de igual dignidade ${ }^{14}$ (SOUZA,2012, p.153-165)

É claro que não se trata de um quadro estático. Desde sempre, como aliás, o próprio texto de Taylor corrobora, os grupos oprimidos ou marginalizados reagem à sua condição. No entanto, este diagnóstico serve para situar a importância das lutas por igual respeito nas sociedades contemporâneas e em especial de países de grandes desigualdades sociais como o Brasil. Neste sentido, a luta por reconhecimento, para além de sua utilidade em termos de multiculturalismo ou tolerância, pode ser, e essencialmente parece que deva ser, uma luta por igual respeito ou igual consideração entre as pessoas. É essa dimensão tanto em um nível normativo quanto sociológico, que o pensamento de Taylor

\footnotetext{
${ }^{14}$ Não faz parte do escopo deste artigo analisar em si a pertinência da tese de Jessé Souza. Cito-o aqui como exemplo de um programa de pesquisa que habilita essa "nova" visão acerca da Política do Reconhecimento. Fiz, no entanto, uma análise mais pormenorizada da tese de Jessé Souza em CARNEIRO, Carlos David. A Subcidadania e o Direito: da sociologia da inautenticidade à modernização seletiva, 2013. Dissertação (Mestrado em Teoria e Filosofia do Direito) - Faculdade de Direito da Universidade do Estado do Rio de Janeiro, Rio de Janeiro, 2013.
} 
Revista da Faculdade de Direito-RFD-UERJ- Rio de Janeiro, n. 28, dez. 2015

parece conferir à situação concreta de sociedades como a brasileira. Creio que essa leitura ofereça uma ampliação importante do escopo da recepção da teoria de Taylor entre nós.

\section{8 - O Reconhecimento como estima do Outro}

Como estive discutindo anteriormente, a política do reconhecimento de Taylor pode ser interpretada em primeira instância como um requisito ou uma ferramenta do igual respeito entre os indivíduos e culturas. Porém, como visto, Taylor vai além, reivindicando não apenas o "respeito" ou um tratamento igual, mas também uma abertura às razões do outro, à sua cultura e valores substanciais. Passamos aqui do reconhecimento como respeito, para uma espécie de reconhecimento como estima e abertura à diferença.

Segundo Taylor, apenas presumir o valor igual entre as pessoas e culturas, sem adentrar de fato em seu conteúdo, seria como que assumir um tipo de condescendência distante, o que longe de configurar uma verdadeira assunção de igual valor, resvalaria apenas em uma gramática formal, sem conteúdo substantivo. Em segundo lugar, Taylor considera que, quando analisamos uma cultura somente munidos de nossos próprios padrões culturais, sem perscrutar as razões alheias, caímos facilmente no etnocentrismo, julgando as outras culturas segundo nossos próprios padrões. Em terceiro lugar, uma simples presunção de valor igual, se não promover um real encontro com a diferença, seria paradoxalmente homogeneizadora e não faria justiça ao ideal do reconhecimento.

É justamente essa ultima crítica que o filósofo faz tanto a alguns dos defensores do multiculturalismo quanto aos filósofos que chama de neonietzscheanos, que incluiriam autores como Foucault e Derrida, que questionando prima facie a própria possibilidade de comparações entre as razões culturais, falhariam em ir ao verdadeiro encontro do outro. O que Taylor propõe, ao contrário, como anteriormente assinalado é uma "fusão de horizontes", que seria construída sob o desenvolvimento de novos vocabulários de comparação voltados a articular os contrastes advindos do encontro entre os diferentes. Essa ideia pode ser melhor explicada se tomamos como parâmetro o artigo "Comparação, 
Revista da Faculdade de Direito-RFD-UERJ- Rio de Janeiro, n. 28, dez. 2015

História e Verdade", no qual Taylor se esmera em traçar a distinção entre as ciências humanas e as ciências naturais no que diz respeito a objetividade dos seus julgamentos.

Segundo o filósofo canadense, uma marca fundamental das ciências naturais nos dias de hoje seria buscar identificar e então neutralizar as características de como vemos o mundo que dependem de nossas próprias particularidades. Com isso, Taylor tem em mente que um procedimento padrão das ciências naturais seria o de evitar que partíssemos, no processo de investigação dos fenômenos, de nossas preconcepções ou julgamentos pessoais de mundo. Estas deveriam ser preteridas em favor de um "método" ou um "procedimento" de análise "desengajados" de qualquer compreensão particular"

Esse procedimento, segundo o filósofo, seria impossível nas ciências humanas. Se objetivo das ciências humanas é tornar as pessoas inteligíveis, e não simplesmente prever o seu comportamento, temos que recorrer a um outro gênero de compreensão dos assuntos humanos que estabeleça as formas e os limites da inteligibilidade. Cada um de nós compreende o mundo a partir de um horizonte e boa parte dessa compreensão permanece inarticulada, moldando nossos juízos sem que nos demos conta disso. No entanto, é justamente nessas compreensões que deveríamos nos apoiar, a fim de torna-las inteligíveis as outras pessoas. Isso porque é essa compreensão que instaura, em primeiro lugar, as formas e os padrões de inteligibilidade para nós (TAYLOR, 2000, p.166).

Como então fugir dos campos e padrões etnocêntricos de compreensão de pessoas e grupos de outras nacionalidades e culturas? É justamente para responder a esta pergunta que o autor lança mão da ideia gadameriana de uma "fusão de horizontes". Segundo Taylor, o encontro com outras culturas e realidades expande os horizontes prévios de compreensão dos indivíduos, refazendo-lhe as formas e limites. Isso significa que articulo coisas antes puramente implícitas a fim de questioná-las. Em particular, articulo o que antes eram limites de inteligibilidade a fim de vê-los em um novo contexto, não mais como estruturas incontornáveis da motivação humana, mas como uma dentre várias possibilidades.

\footnotetext{
${ }^{15}$ O Antropólogo Clifford Geertz elabora uma crítica interessante a respeito da visão de Charles Taylor sobre as ciências naturais em GEERTZ, Clifford. O estranho estranhamento: Charles Taylor e as Ciências Naturais. In: Nova Luz sobre a Antropologia. Rio de Janeiro: Zahar, 2001.
} 
Revista da Faculdade de Direito-RFD-UERJ- Rio de Janeiro, n. 28, dez. 2015

Eis o motivo, para Taylor, de a outro-compreensão alterar a auto-compreensão, promovendo em particular nossa libertação de alguns dos mais fixos contornos de nossa cultura anterior. De certa maneira, só liberamos os outros e "os deixamos ser" quando podemos identificar e articular um contraste entre a sua e a nossa compreensão, modificando também nossos horizontes prévios (TAYLOR, 2000, p.166-167). O objetivo, assim, parece ser criar uma linguagem comum, uma compreensão humana comum, que permita que tanto "nós" quanto "eles" sejamos compreendidos da maneira menos "distorcida" possível.

Restaria perguntar, no entanto, se há, de fato, algo de objetivo neste empreendimento. O grande problema neste tipo de questionamento, segundo Taylor, é que, ao fazê-lo, estamos condicionados a buscar parâmetros de "objetividade" no modelo das ciências naturais, como se estabelecer uma linguagem comum com os Zulus fosse o mesmo fazer um relato livre de perspectivas sobre partículas subatômicas. De fato, este tipo de objetividade, não pode ser alcançado com a fusão de horizontes, por motivos já descritos. No entanto, o que se pode galgar em termos de objetividade, como anteriormente assinalado, é um relato cada vez menos distorcido sobre o outro.

Taylor pede, a título de exemplo, que imaginemos um grupo de estudiosos cristãos e mulçumanos que tenha elaborado, com grande esforço e compreensão ecumênica, uma linguagem em que suas diferenças possam ser indistorcidamente expressas e que isso tenha satisfeito ambos os lados. Teríamos aí um grande ganho em termos de objetividade, mas, ainda assim, não podemos dizer que criamos uma concepção religiosa objetiva e isenta de pontos de vista. O esforço teria de recomeçar se qualquer um dos lados decidisse, por exemplo, entender-se com os budistas (TAYLOR, 2000, p.168). Segundo Taylor, o único ideal possível de objetividade nesse domínio é o da inclusividade que, através da fusão de horizontes, supera a cada encontro estreitezas e distorções em relação ao outro.

Como ressaltado anteriormente, um dos motivos para Taylor rejeitar a simples presunção do valor igual das culturas como limite último da gramática política, preferindo a "solução" da fusão de horizontes seria justamente evitar algum tipo de condescendência ou falsa consideração ou respeito por aquilo que nem nos propomos a conhecer de fato. No entanto, adentra-se com isso em uma série de discussões controversas acerca da 
Revista da Faculdade de Direito-RFD-UERJ- Rio de Janeiro, n. 28, dez. 2015

própria possibilidade de "comparação" entre o valor das culturas. Tema tanto mais polêmico quando temos em mente que não raro "comparações" entre as culturas ao longo da história não raro levaram à inúmeras violências, racismo e subjugação. E se, ao fím e ao cabo, chegamos a uma conclusão de fato desfavorável em relação ao outro?

Taylor parece admitir que este seja, afinal, o preço do encontro real. Encontrarme com o outro e com ele elaborar uma linguagem comum de contrastes e comparações pode de fato levar-me a acreditar em uma certa superioridade cultural das democracias ocidentais, por exemplo, em relação à evitação do sofrimento desnecessário ou ao reconhecimento de direitos fundamentais. De outro lado, posso descobrir um sem número de riquezas e valores de outras civilizações que representam um ganho em relação à minha cultura, como, por exemplo, a relação mais harmônica estabelecida por certos povos tradicionais com a natureza ou maneiras de neutralizar o risco do atomismo e da anomia social vivenciada nas democracias chamadas de "pós-industriais". O que diferiria lapidarmente este tipo de juízo de uma pré-compreensão etnocêntrica é justamente o fato de ele ser precedido por uma "fusão de horizontes" e de uma presunção de igual valor como base do meu engajamento no conhecimento do outro.

O modo de proceder deste tipo de juízo pode ser melhor explicado se recorrermos a um outro ensaio de Taylor intitulado "Explicação e Razão Prática". Nele, seguindo Alasdair MacIntyre ${ }^{16}$, Taylor defende que a apreciação axiológica de duas tradições pode ser feita racionalmente, não através de uma metateoria acerca do raciocínio prático ou de critérios previamente estabelecidos, mas demonstrando se a passagem de uma tradição para a outra representa ou não um ganho em termos de compreensão de problemas comuns a ambas (TAYLOR, 2000, p.55).

Em sumo, o filósofo defende que ao comparar duas culturas ou tradições sob uma linguagem comum, posso mostrar uma superioridade entre uma ou outra no sentido de que posso dar uma melhor explicação das dificuldades internas da tradição do interlocutor do que este próprio o faria. Posso ainda apresentar um desenvolvimento tido por ambos os lados como positivo que não pode ser explicado nos próprios termos do interlocutor.

16 MacIntyre esboça um modelo de raciocínio prático similar ao desenvolvido por Taylor em MACINTYRE, Alasdair. After Virtue. Londres: Bloomsbury, 2011. 
Revista da Faculdade de Direito-RFD-UERJ- Rio de Janeiro, n. 28, dez. 2015

Em terceiro lugar, posso mostrar que uma transição de uma posição específica em relação a outra pode ser descrita como um movimento intrinsecamente redutor de erros. Todas essas passagens, baseadas em contrastes e não em categorias pré-definidas, ainda delegam à razão alguma capacidade de formular juízos práticos e arbitrar diálogos entre indivíduos culturas aparentemente irreconciliáveis (TAYLOR, 2000, p.68).

Nada disso, como o próprio Taylor reconhece, garante que todas as disputas ou questões práticas sejam de fato arbitráveis pela razão. Ainda mais questões controversas que separam as diferentes culturas e suas formas de vida e relacionamento mútuo. No entanto, a possibilidade de uma fusão de horizontes e os recursos ainda disponíveis da razão prática mostrariam, para o filósofo, que não se pode renunciar à razão cedo demais.

\section{9 - O Reconhecimento e o autogoverno coletivo}

Como vimos anteriormente, uma das principais críticas de Taylor ao liberalismo procedimental em "A Política do Reconhecimento" diz respeito à sua suposta incapacidade de avançar no reconhecimento das diferenças, uma vez que seu requisito de "neutralidade" falharia ao considerar as demandas substantivas dos grupos e cidadãos e transformá-las em políticas de Estado. Esta crítica foi desenvolvida ainda em dois textos posteriores à "Política do Reconhecimento", intitulados "The Dynamics of Democratic Exclusion" (TAYLOR, 1998b) e "Democratic Exclusion (and its remedies?)" (TAYLOR, 2011). Pode-se dizer que, em ambos os textos a crítica de Taylor ao liberalismo procedimental consiste em afirmar que, ao negar o reconhecimento das demandas substantivas dos atores sociais na esfera pública, este modelo acabaria passando a "mensagem" de que estes grupos não fariam parte ou não teriam vez na sociedade.

A crítica de Taylor, no entanto, vai mais além, não se relacionando somente ao escopo daquilo que pode ou não ser permitido como "assunto ou razão pública", mas da própria compreensão normativa do que significa a democracia e de como poder-se-ia, na dimensão da teoria social, analisa-la nas sociedades contemporâneas. O ponto central para Taylor, é que, desde sempre, a democracia fora entendida como um empreendimento 
Revista da Faculdade de Direito-RFD-UERJ- Rio de Janeiro, n. 28, dez. 2015

coletivo, que demanda por isso mesmo a construção de uma identidade comum e negociação recíproca entre os cidadãos e suas pretensões expressivas (TAYLOR, 1998b, p.1).

No mesmo sentido, em artigo intitulado "O Debate Liberais-Comunitários: Propósitos Entrelaçados" Taylor aponta como uma das principais fraquezas do liberalismo procedimental o fato de este não conseguir sustentar em seus próprios termos as bases para a coesão e a reprodução das comunidades políticas. Ao deixar escapar elementos como a importância de uma história em comum ou a identificação dos indivíduos uns com os outros e com suas instituições, o liberalismo procedimental, além de não conseguir explicar as condições de sua reprodução em seus próprios termos, não seria capaz de promover os laços comunitários essenciais para o desenvolvimento das sociedades e não conseguiria enfrentar de modo satisfatório os atuais dilemas das sociedades contemporâneas.

Mais do que isso, para Taylor, o liberalismo procedimental não conseguiria capturar dimensões importantes da experiência social, como o autogoverno coletivo, tratado por esta modalidade de pensamento como uma relíquia própria das antigas repúblicas. O que, no entanto, parece separar o filósofo canadense definitivamente dos liberais procedimentais é retomar o debate acerca da existência de bens que só podem ser gozados em comum. Ao estabelecer a centralidade desses bens, cuja construção e usufruto dependem não raro dos espaços de deliberação pública, há um deslocamento sensível do significado atribuído à política. (TAYLOR, 2000, p.205-220).

É neste ponto, também, que o pensamento do filósofo canadense aproxima-se dos temas hegelianos, que por vezes permeiam suas obras, a despeito ou não de menções explícitas. Não se pode dizer sem engano, todavia, que Taylor seja um autor hegeliano no sentido de tomar a ontologia ou a filosofia da história de Hegel como pressupostos teóricos, mas no sentido de reabilitar alguns dos problemas colocados por este teórico no debate contemporâneo

Em seu "Hegel and Modern Society", Taylor defende que a uma ideia primordial de Hegel para as sociedades contemporâneas continua sendo a ideia de eticidade (Sittlichkeit). Segundo o filóso canadense, este termo referir-se-ia às identificações e 
Revista da Faculdade de Direito-RFD-UERJ- Rio de Janeiro, n. 28, dez. 2015

obrigações morais que tenho com a comunidade da qual faço parte. A comunidade seria então compreendida como uma substância ética que transcende os próprios indivíduos, que só poderiam alcançar a inteligibilidade de suas próprias ações em referência aos horizontes partilhados nela (TAYLOR, 1998, p.93).

Apesar de se afastar dos pressupostos ontológicos que guiam essa ideia em seu sentido original, no qual o indivíduo e a comunidade são um veículo de um espírito cósmico retornando à sua autoconsciência, Taylor considera que Hegel teria tido a virtude de promover, através deste termo, a ideia de uma realidade maior na qual os homens estariam imersos. Nestes termos seria possível ainda, segundo filósofo canadense, falar em um "espírito coletivo", no sentido de que certas ideias permeiam a sociedade como um todo e não apenas alguns indivíduos. Afinal, durante toda a história humana os homens viveram e vivem relações cujos significados são forjados e expressos sobretudo na vida pública de suas sociedades. (TAYLOR, 1998, p.94).

Assim, o filósofo canadense parece encontrar em Hegel a dimensão que falta na abordagem do liberalismo procedimental sobre a vida política da sociedade: a dimensão das relações intersubjetivas de reconhecimento e produção normativa de significados e valores sociais partilhados pelas sociedades. A análise das relações que se dão nessa dimensão, para Taylor, pode redimensionar a compressão das principais "patologias" sociais que marcam as sociedades contemporâneas. E o elo fundamental dessas patologias seria justamente o atomismo social, que tende a ver os indivíduos como desvinculados de seus contextos e processos históricos, reduzindo-os a produtores e reprodutores de padrões de interação meramente utilitárias.

Apesar de não atribuir essas patologias unicamente ao "liberalismo procedimental", Taylor considera que ele teria ajudado a aprofundá-lo ao elidir dimensões fundamentais da política, um erro que, por sua vez, Hegel não cometera. Hegel estaria atento já a seu tempo, a elementos constitutivos das patologias da modernidade, como os perigos da anomização social, advinda da modernização política e econômica, a dissolução comunitária frente aos interesses privados e a homogeneização social marcada pela reconfiguração do mercado e erosão dos subgrupos sociais que tendiam a dar sentido à vida de grande parte das pessoas. 
Revista da Faculdade de Direito-RFD-UERJ- Rio de Janeiro, n. 28, dez. 2015

Assim, para Taylor, mesmo rechaçando suas respostas e sínteses filosóficas, Hegel continuaria um filósofo atual para se pensar a crise da "eticidade" e os fatores que ameaçam a coesão das sociedades modernas. Seus insights ainda seriam sumamente importantes para evitar tanto as ilusões e distorções de um utilitarismo atomista quanto das contra-ilusões românticas que surgiram em oposição às correntes majoritárias das ciências humanas (TAYLOR, 1998, p.128-134).

Deste modo, o que Taylor vai buscar em Hegel é a necessidade de retorno a uma tentativa de elaborar uma visão da subjetividade corporificada e de um conceito de liberdade que encontra sua expressão nas formas de existência social dadas com referência à própria comunidade. Para o filósofo canadense, encarar dessa forma tanto a subjetividade quanto a liberdade do ser humano poderiam redimensionar o debate político e permitiriam encontrar novas formas de lidar com os problemas contemporâneos

Neste sentido, Taylor não parece oferecer um modelo pronto e acabado dos termos deste projeto e seus desdobramentos políticos. No entanto, como vimos, tanto nas críticas esboçadas ao liberalismo procedimental quanto na defesa dos arranjos institucionais substancialistas implementados pelo Quebec, pode-se antever algumas das consequências práticas deste projeto. A dimensão coletiva da política retornaria em uma dimensão tanto analítica quanto prática e a linguagem da "razão pública" abrir-se-ia às fontes morais profundas e diversas das partes envolvidas.

Se por um lado o projeto de Taylor parece oferecer uma visão mais abrangente tanto acerca dos padrões de interação de fato dados na sociedade e permitir uma maior abertura às questões consideradas essenciais por sujeitos e grupos no espaço político, não poucas são as dúvidas e cautelas que se devem tomar diante de um projeto como esse. Para ficar com apenas dois aspectos importantes, é preciso considerar que uma maior abertura às diferenças e avaliações fortes dos diversos grupos, em vez de promover a coesão social, pode concorrer para fragmentar ainda mais as sociedades plurais, corroendo o já frágil consenso sob o qual estão construídas.

Em segundo lugar, a relação aporética entre direitos individuais e razões comunitárias estabelecida por Taylor, pode assumir feições muito mais dramáticas do que as envolvidas na questão concreta trazida pelo filósofo e sua experiência canadense. 
Revista da Faculdade de Direito-RFD-UERJ- Rio de Janeiro, n. 28, dez. 2015

Enquanto não formos capazes de conciliar, tanto do ponto de vista teórico quanto prático, o direito de liberdade com a dimensão da "eticidade", ainda restam dúvidas se esse ideal comunitário, em se considerando os riscos e dilemas envolvidos, possa fazer frente, enquanto um ideal suficientemente atraente, ao liberalismo procedimental. A não ser é claro, como espera Taylor, que este último torne-se mesmo impraticável no mundo de amanhã.

\section{0 - À Guisa de Conclusão}

Procurei apresentar e discutir alguns dos aspectos de "A política do Reconhecimento" de Charles Taylor, explorando, em seguida, algumas das questões fundamentais envolvidas em seu projeto filosófico. Na primeira parte, apresentei o que considerei serem os principais argumentos de Taylor acerca da importância do reconhecimento no debate político contemporâneo. Como vimos, para Taylor, o reconhecimento configura uma necessidade humana vital devida à indivíduos e grupos sociais. Também discuti como essa ideia foi tornada possível pela erosão das antigas hierarquias sociais baseadas na ideia de honra e pela eficácia social da política da igual dignidade.

Discuti ainda que, para Taylor, o reconhecimento político se dá tanto no reconhecimento público do que há de igual em todos os indivíduos, quanto no reconhecimento de suas diferenças e que seu projeto, em oposição à neutralidade liberal, consiste tanto em assumir a possibilidade de incluir agendas eticamente substantivas no espaço político, como em habilitar um diálogo mais profundo entre indivíduos e culturas diferentes, através de uma "fusão de horizontes".

Em seguida, na segunda parte deste artigo, procurei esboçar uma análise crítica de "A política do reconhecimento", abordando três eixos principais. Em primeiro lugar, procurei enfatizar como a política do reconhecimento, se também entendida como política da igual dignidade, pode transcender a agenda com a qual é comumente associada (a do multiculturalismo e das lutas identitárias) para ser também um parâmetro normativo da luta pela cidadania igual. Em segundo lugar, defendi como o pensamento do filósofo 
Revista da Faculdade de Direito-RFD-UERJ- Rio de Janeiro, n. 28, dez. 2015

canadense epode ser usado como parâmetro analítico para as sociedades que ainda lutam para consolidar a política da igual dignidade, como a brasileira. Aqui, muni-me especialmente da tese acerca da "Construção Social da Subcidadania", do sociólogo Jessé Souza.

Em segundo lugar, procurei mostrar como Taylor parece oferecer um redimensionamento do debate político através de sua ideia de "fusão de horizontes", no qual, para além da ideia de respeito e neutralidade, se esmera em construir a possibilidade de um real diálogo entre os diferentes, habilitando assim um debate mais substancial no espaço político, sem excluir a mediação racional. A principal contribuição deste tipo de categoria, segundo discuti, seria a de reabilitar temas tidos por versões mais usuais de "liberalismo" como impassíveis de figurar no espaço público, como religião e identidades culturais, muitas vezes tidas como questões de foro íntimo.

Por fim, procurei apresentar a visão de Taylor sobre a democracia como autogoverno coletivo, visão esta presente tanto em "A política do reconhecimento" como em outros textos do autor. Aqui, mostrei que as principais críticas de Taylor ao liberalismo procendimental, além da incapacidade de reconhecimento das diferenças, consistem na sua suposta incapacidade de manter a coesão e a reprodução consciente das sociedades políticas e como Taylor pretende recuperar a ideia de um "autogoverno coletivo" e a ideia de que certos bens só podem ser gozados em "comum".

Ao analisar estes pontos, procurei fazer jus ao meu objetivo inicial de responder em que medida "A política do Reconhecimento" de Taylor ajuda a redimensionar o debate político das sociedades contemporâneas. A meu ver, a principal vantagem de um projeto como o de Taylor é resgatar a dimensão intersubjetiva e comunitária da política, com ganhos tanto normativos quanto analíticos para o tema. Aliás, é a própria existência dessa dimensão que torna possível falar em uma luta "intersubjetiva por reconhecimento", uma vez que, como vimos, ancorados nos padrões normativos reconhecidos na comunidade, os indivíduos e grupos lutam para terem sua dignidade e identidade reconhecidas. Conforme afirmei anteriormente, no entanto, parecem faltar ainda ao filósofo canadense mediações necessárias para o desenvolvimento de seu projeto. 
Revista da Faculdade de Direito-RFD-UERJ- Rio de Janeiro, n. 28, dez. 2015

Isso porque se a nível teórico fica clara a relação entre a necessidade antropológica do reconhecimento e a abertura da comunidade às razões e expressões profundas do indivíduo, em um nível prático a relação entre direitos individuais e projetos coletivos permanecem como uma aporia. Não sei até que ponto esse é um limite de Taylor ou da própria razão teórica. De qualquer maneira, resta aqui um desafio importante ao pensamento do filósofo canadense para que seja considerado, afinal, um ideal suficientemente atraente em oposição ao liberalismo procedimental.

\section{1 - Referências Bibliográficas}

BERGER, Peter. On the Obsolescence of the Concept of Honour. In: HAUERWAS, Stanley; MACINTYRE, Alasdair. Revisions: Changing Perspectives in Moral Philosophy. Notre Dame: University of Notre Dame Press, 1983.

CARNEIRO, Carlos David. A Subcidadania e o Direito: da sociologia da inautenticidade à modernização seletiva, 2013. Dissertação (Mestrado em Teoria e Filosofia do Direito) Faculdade de Direito da Universidade do Estado do Rio de Janeiro, Rio de Janeiro, 2013.

FRASER, Nancy. "From Redistribution to Recognition? Dilemmas of Justice in a 'Postsocialist Age". In:

Justice Interruptus - Critical Reflections in a

'Postsocialist Condition. Londres. Routlege, pp. 11-39, 1997

GARGARELLA, Roberto. As Teorias da Justiça Depois de Rawls: Um Breve Manual de Filosofia Política. São Paulo: WMF Martins Fontes, 2008.

GEERTZ, Clifford. O estranho estranhamento: Charles Taylor e as Ciências Naturais. In: . Nova Luz sobre a Antropologia. Rio de Janeiro: Zahar, 2001

KYMLICKA, Will. Filosofia política contemporânea. São Paulo: Martins Fontes, 2006.

MACINTYRE, Alasdair. After Virtue. Londres: Bloomsbury, 2011.

MENDONÇA, Ricardo. A dimensão intersubjetiva da autorrealização: em defesa da teoria do reconhecimento. In: Revista brasileira de Ciências Sociais, vol.24, $\mathrm{n}^{\circ}$ 70, PP.143-154, 2009. 
Revista da Faculdade de Direito-RFD-UERJ- Rio de Janeiro, n. 28, dez. 2015

PRODI, Paolo. Uma história da justiça. Martins Fontes: São Paulo, 2005.

SOUZA, Jessé. A Construção da Social da Subcidadania: Para uma Sociologia Política da Modernidade Periférica. Rio de Janeiro: IUPERJ, 2006.

TAYLOR, Charles. As fontes do Self. São Paulo: Edições Loyola, 1997.

Argumentos Filosóficos. São Paulo: Edições Loyola, 2000.

Democratic Exclusion (and it remedies?).

In:_. Dilemmas and Connections. Cambridge, MA: Harvard University Press, 2011. 124-145.

. Politics of Recognition. In: GUTMANN, Amy (org). Multiculturalism: Examining the Politics of Recognition. Princeton: Princeton University Press, 1994.

Press, 1998.

Hegel and Modern Society. Cambridge: Cambridge University The dynamics of Democratic Exclusion. In: Journal of Democracy. Vol.9, no. 4, 1998b. p.143-156.

THOMPSON, Simon. The political theory of recognition: a critical introduction. Cambridge, UK/Malden: Polity, 2006. 